\title{
THE PAN-AMERICAN LEAGUE FOR THE STUDY AND CONTROL OF RHEUMATIC DISEASES
}

BY

LORING T. SWAIM

There has recently been established a PanAmerican League for the Study and Control of Rheumatic Diseases, consisting of the following countries: Argentina, Brazil, Canada, Chile, Mexico, Paraguay, Peru, Uruguay, United States of America. The officers of the League are: President.-Dr. Ralph Pemberton, Philadelphia, Pa., U.S.A.; VicePresident.-Dr. Anibal Ruiz-Moreno, Buenos Aires, Argentine, S.A.; Secretary-Dr. Loring T. Swaim, Boston, Mass., U.S.A.; Treasurer-Dr. Fernando Herrera Ramos, Montevideo, Uruguay, S.A. The full list of delegates to the Central Committee of the League from the various countries is not yet at hand. However, so far as the United States is concerned, the following have been appointed: Lt.-Col. Philip S. Hench (M.C., U.S. Army); Dr. Richard H. Freyberg. Representatives to the Regional Committee are: Col. Walter Bauer (M.C., U.S. Army); Dr. Donald F. Hill.

The objectives of the Pan-American League as drawn up in the Statutes are as follows: " $(a)$ to strengthen the cultural bonds between the countries of North and South America; (b) to further efforts to alleviate suffering from rheumatic diseases and to institute measures of prevention; $(c)$ to compile and disseminate knowledge and information regarding rheumatism in the respective countries; (d) to unify the nomenclature and classifications; $(e)$ to promote scientific investigation; $(f)$ to hold Pan-American Congresses on the rheumatic diseases".

It is obvious, of course, that at the present time - and perhaps for some time to come-the holding of a congress will be out of the question because of difficulties of transportation. In spite of this, it is clear from experience acquired during development of the League that much can be, and indeed has already been, accomplished, chiefly by correspondence, in the direction of implementing the League's purposes, at least in a preliminary way. In some countries comprising the League distinct impetus has been given to consideration by the medical profession of the large group of conditions coming under the head of rheumatic diseases. In certain other countries interest has been created where apparently little or none existed before, so that from the broad sociologic standpoint definite gains have been recorded which might otherwise have required many years for development.
Another result forthcoming from the international correspondence necessarily involved in forming the League is inauguration of a correlation of clinical experiences in several of the countries concerned, bearing upon the types of rheumatism encountered and the races in which they occur. Hardly a beginning has been made in this connection, but the way is now open for exploration of the incidence of rheumatic diseases under the varied conditions of climate, altitude, race, and nutrition, which are involved in the wide area covered by the League's interests, extending as they do from Hudson Bay to Tierra del Fuego. An extensive and critical study of such a condition as rheumatic fever in subtropical and tropical countries would doubtless reveal facts of great significance. Perhaps nothing of greater importance presents before the League than that of obtaining full and accurate statistics bearing upon the several problems just mentioned. It is hoped that those physicians privileged to take part in the forward looking movement constituting the Pan-American League will turn their energies at an early moment to this end. A way must of course be found for making available to all the members of the League such statistics and correlations of clinical experiences as may develop, though at the moment the means to this end are not clearly indicated. Several possibilities are under consideration, however, and it is expected that in course of time this desideratum will become an actuality. Many other examples could be cited of the advantages already gained by contact, even by mail, between the various workers in this field in the several countries concerned.

With establishment of the Pan-American League, which had its incipiency with Dr. Anibal RuizMoreno and his colleagues in Buenos Aires, something should be said as to its relation to the Ligue Internationale contre le Rhumatisme from which, indirectly, it sprang. The original prospectus of the Pan-American League expressly set forth that it is in no sense meant to act as a substitute for the Ligue Internationale but rather as an amplification and implementation of the older Ligue's purposes. It is abundantly clear that for the present, and presumably for some time to come, many of the nations of Europe will not be able to further effectively the objectives and activities of the Ligue Internationale. In a sense, therefore, the Pan-American League can 
be regarded as the child of the Ligue Internationale, having among its other functions that of keeping alive and developing international interest and collaboration in the field of rheumatic disease. When peace finally reigns throughout the world the PanAmerican League can then take its place as an integral though discrete part of the older organization. On the other side of the picture it is clear that the war has provided intensive and additional experience in the armies of some of the countries involved, as to the incidence and nature of certain phases of the major problem-for example, rheumatic fever, so-called psychogenic rheumatism, psycho-somatic rheumatism, and fibrositis and it would be highly desirable as soon as practicable to extend to all countries of the Pan-American League as full information, in these connections, as may be available for prevention and control.

One other point needs comment-namely, in regard to paragraphs $(a)$ and $(c)$ of the objectives of the Pan-American League. The influence of cooperation in the world of science is by definition limited in a political sense, but co-operation nevertheless may contribute to a rapprochement which often transcends all barriers. It is not too much to hope, therefore, that the Pan-American League will exercise at least a tacit influence in the direction of international amity.

Finally, in spite of the limitations imposed upon travel, it is hoped that members of those countries in which rheumatic diseases have not been intensively studied will feel inclined to visit those other countries where, of necessity, these diseases have compelled and obtained active attention from both the lay and medical public. So far as the United States is concerned, the officers and members of the American Rheumatism Association would welcome visits from any of their colleagues in the other Americas and would deem it a privilege to show them whatever may be going on of interest. 